\title{
Design and parameters optimization for cutting-conveying mechanism of ramie combine harvester
}

\author{
Jicheng Huang ${ }^{1,2}$, Kunpeng $\operatorname{Tian}^{1}$, Cheng Shen ${ }^{1,3 *}$, Bin Zhang ${ }^{1,3}$, \\ Haolu Liu ${ }^{1}$, Qiaomin Chen ${ }^{1}$, Xianwang $\mathrm{Li}^{1}$, Aimin $\mathrm{Ji}^{2}$ \\ (1. Nanjing Institute of Agricultural Mechanization, Ministry of Agriculture and Rural Affairs, Nanjing 210014, China; \\ 2. College of Mechanical and Electrical Engineering, Hohai University, Changzhou 213022, Jiangsu, China; \\ 3. School of Mechanical Engineering, Southeast University, Nanjing 211189, China)
}

\begin{abstract}
In order to solve the problems of uneven stubble, low cutting efficiency and frequent breaking and blocking in the cutting and conveying links of ramie combine harvester, a reciprocating double movable blades cutter and a double-layer chain conveyor were designed, and the operating parameter test and optimization were carried out by using the central combination test design theory, with the emphasis on the influence of the forward speed, the cutting speed of the cutter and the conveying speed of the chain on the cutting efficiency, the failure rate and the conveying rate, and the multi-objective optimization was carried out based on these response indicators. Firstly, the structure and operating parameters of the cutting-conveying mechanism of ramie combine were studied. Then, the experiment was designed by the quadratic orthogonal rotation combination test method, and the data is processed by Design-Expert. The regression mathematical model of cutting efficiency, failure rate and conveying rate was established and variance analysis was carried out. By analyzing the effect of interaction of various factors on cutting efficiency, failure rate and conveying rate by response surface methodology, and performing multi-objective optimization on the regression model according to the importance of the optimization target, the optimal combination of the operating parameters of the cutting-conveying parts of the ramie combine harvester was obtained: when the forward speed was $0.85 \mathrm{~m} / \mathrm{s}$, the cutting speed was $1.40 \mathrm{~m} / \mathrm{s}$, and the chain conveying speed was $1.33 \mathrm{~m} / \mathrm{s}$, the cutting efficiency and conveying rate were the maximum and the failure rate was the minimum, with the values of 44.36 plants/s, $93.60 \%$ and $4.16 \%$, respectively. The optimized parameters were verified in the field on the ramie combine harvester. In the field test, the cutting efficiency, conveying rate, and failure rate were 43.80 plants/s, $92.45 \%$, and $4.52 \%$, respectively, and the relative errors with the optimized values were $1.3 \%, 1.2 \%$, and $8.7 \%$, respectively, which was relatively consistent.

Keywords: ramie, harvester, operating parameters, multi-objective optimization, response surface

DOI: $10.25165 /$ j.ijabe.20201306.5952
\end{abstract}

Citation: Huang J C, Tian K P, Shen C, Zhang B, Liu H L, Chen Q M, et al. Design and parameters optimization for cutting-conveying mechanism of ramie combine harvester. Int J Agric \& Biol Eng, 2020; 13(6): 94-103.

\section{Introduction}

Ramie (Boehmeria nivea L. Gaud.), a perennial plant of Urticaceae, originated in China, is a traditional characteristic industrial fiber crop in China, with a planting history of more than 4700 years, also known internationally as "China grass" or "Nanking grass" $"[1-3]$. Ramie is widely planted in the Yangtze River Basin and the south of China. At present, China is the

\section{Received date: 2020-06-09 Revision date: 2020-09-03}

Biographies: Jicheng Huang, Assistant Professor, research interests: agricultural mechanization engineering, Email: huangjicheng@caas.cn; Kunpeng Tian, Assistant Professor, research interests: agricultural mechanization engineering, Email: tiankp2005@163.com; Bin Zhang, Professor, research interests: agricultural engineering, Email: xtsset@hotmail.com; Haolu Liu, research assistant, research interests: agricultural engineering, Email: liuhaolu@caas.cn; Qiaomin Chen, Professor, research interests: agricultural engineering, Email: nnncqm@163.com; Xianwang Li, Professor, research interests: agricultural engineering, Email: xw3871@163.com; Aimin Ji, Professor, research interests: optimum structural design, Email: jiam@hhuc.edu.cn.

*Corresponding author: Cheng Shen, Assistant Professor, research interests: agricultural mechanization engineering, Nanjing Institute of Agricultural Mechanization, Ministry of Agriculture and Rural Affairs, No.100 Liuying, Xuanwu District, Nanjing 210014, China. Tel: +86-25-84346078, Email: shencheng@caas.cn. largest ramie producer in the world, with the largest planting area and output, accounting for more than $90 \%$ of the world's total planting area and output. Brazil, Philippines, India, Laos and other countries also plant ramie on a small scale ${ }^{[4]}$. Ramie is widely used as an ideal plant protein crop for forage, which is rich in nutrients such as protein, lysine, carotenoid and calcium ${ }^{[5-7]}$; the root of ramie is a kind of traditional Chinese medicine, with multiple pharmacological activities such as hemostasis, analgesic, detoxification, antiviral, bacteriostasis, liver protection ${ }^{[8,9]}$; ramie fiber, as a type of environmental-friendly and low-cost biological resource, is one of the preferred materials for composite material reinforcement, with the advantages of long length, high crystallinity and large modulus of elasticity ${ }^{[10-12]}$; the stalks of ramie are also high-quality raw materials for papermaking, carbon powder and edible fungus substrate $e^{[13,14]}$.

At present, the research on ramie mechanization in China is mainly focused on green forage combine harvester and ramie stripping machine ${ }^{[15-19]}$. Ramie harvesting is mainly carried out by other harvesting machines used for high stalk crops, such as windrower, hemp harvester, reed harvester, corn harvester ${ }^{[20-24]}$. There is no special ramie harvesting machine, which results in poor harvesting effect. Nanjing Institute of Agricultural Mechanization, Ministry of Agriculture and Rural Affairs, has carried out research on ramie harvesting machinery. The designed 4LMZ160 crawler 
ramie combine harvester can complete the functions of cutting, conveying and collecting at one time, which can partially meet the requirements of ramie harvesting, but the quality of operation needs to be further improved ${ }^{[25]}$. In the early 1990s, Japan once tried to develop ramie harvester by using sensing technology, even designed drawings and test devices, but failed to carry out in-depth research, and the prototype structure has not been reported. In Europe, there are researches on the harvesters of hemp, flax and kenaf, but there is no data query on ramie harvesters ${ }^{[26,27]}$.

Based on the research of the self-developed ramie combine harvester, the relationship between operating parameters of cutting and conveying parts and operating quality is studied by taking cutting efficiency, failure rate and conveying rate as the target and combining with field trial. Firstly, the factors that have great impact on the operating quality are screened out: the forward speed, the cutting speed of the cutter and the conveying speed of the chain. Then the response surface of cutting efficiency, failure rate and conveying rate is established by three-factor three-level response surface test, and the response surface is analyzed to fit the quadratic regression curve and get the regression equation. The influence of each factor on the operating quality evaluation index, as well as the best combination of parameters are explored in order to guide the field operation of ramie combine harvester and provide a reference for the design of ramie combine harvester.

\section{Overall structure and operating principle}

The ramie combine harvester is composed of a chassis system, a cab system, a reciprocating double movable blades cutter and a double-layer chain conveyor, an upper stalk-guiding device, a baling device, etc. The overall structure is shown in Figure 1.

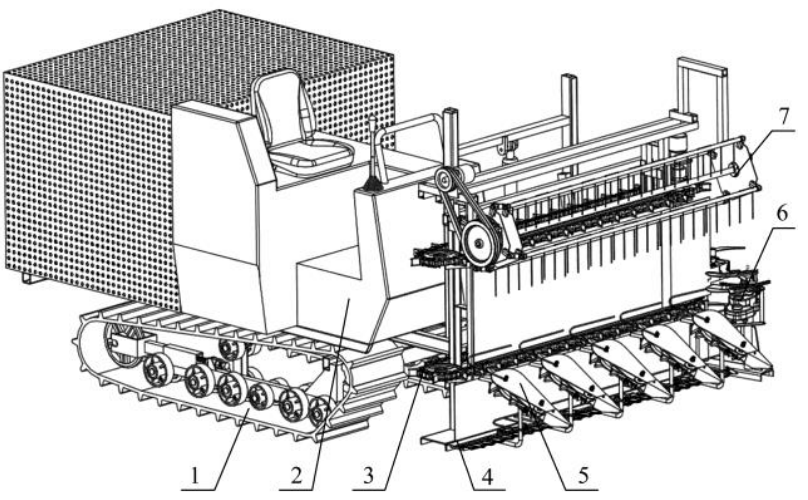

1. Chassis system 2. Cab system 3. Double-layer chain conveyor 4. Reciprocating double movable blades cutter 5. Lower stalk-splitting and stalk-holding device 6. Baling device 7. Upper stalk-guiding device

Figure 1 General structure schematic of ramie combine harvester

The operation process is as follows: Firstly, the height of the header and the upper stalk-guiding device is adjusted by a hydraulic cylinder, that is, the height of the teeth of the upper stalk-guiding device shall be basically the same as that of the middle and upper part of the ramie stalk, so as to make the stubble height meet the design requirements; then the harvester moves forward; under the joint action of the lower stalk-splitting and stalk-holding device and the upper stalk-guiding device, the ramie stalks in the working width are picked up and guided to be cut by the reciprocating double movable blades cutter, the stalks cut are horizontally clamped and transported to a baling device under the action of a double-layer chain conveyor, and the baled stalks are collected in the ramie field, so the mechanized harvesting operation of ramie is completed.

\section{Design of key components}

\subsection{Design of reciprocating double movable blades cutter}

The cutting device is one of the key parts of the ramie combine harvester, which is used in conjunction with the conveying device to finish the cutting of the stalk root. The quality of the cutting directly affects the subsequent conveying effect and determines the operation quality of the entire harvester. At present, there are three types of cutters: the first one is reciprocating cutter, whose cutter moves back and forth, and can be further divided into reciprocating single movable blade cutter and reciprocating double movable blades cutter according to the number of movable blade groups; the second one is disc cutter, whose cutter moves in rotation, with stable operation, small vibration, but short service life; the third type is the swinging rotary cutter, whose blade rotates in a plane parallel to the advance direction, with strong cutting ability, and is suitable for high-speed operation ${ }^{[28]}$. In order to prevent ramie fiber from winding the rotating shaft of the disc cutter and reduce the inertia of the single movable blade cutter after cutting, In addition, to improve the cutting quality, the reciprocating double movable blades cutter is adopted in this harvester ${ }^{[29]}$. Its structure is shown in Figure 2.

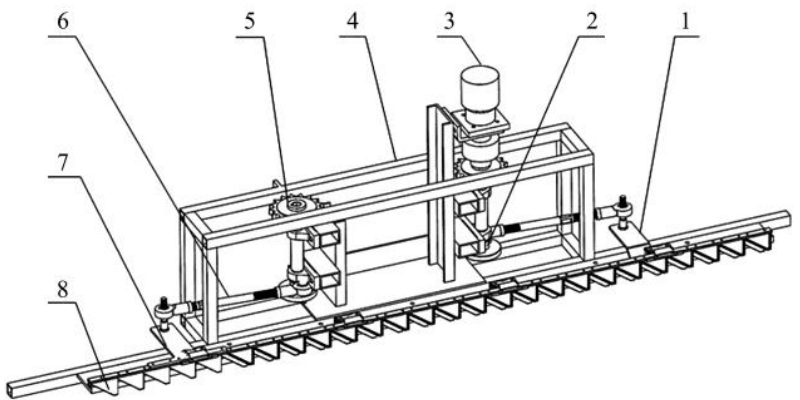

1. Lower knife link arm 2. Eccentric wheel 3. Motor 4. Frame 5. Drive

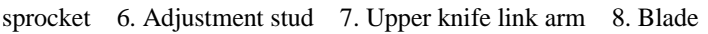

Figure 2 Structure schematic of reciprocating double movable blades cutter

\subsubsection{Analysis of structural parameters of blade}

The reciprocating double movable blades cutter holds the ramie stalks between the blades for cutting. The structural parameters of the blades have a great impact on the operating reliability and power consumption of the cutter. When the width of the blades is selected, the cutting angle $\alpha$ is an important factor that determines the length of the blades and affects the clamping stability and cutting resistance ${ }^{[30,31]}$. Studies have shown that increasing the cutting angle will reduce the cutting resistance, but the excessive cutting angle will affect the clamping stability. The cutting angle is analyzed based on the premise that the ramie stalk is clamped by blades. When ramie stalk is clamped by blades, the force analysis is shown in Figure 3.

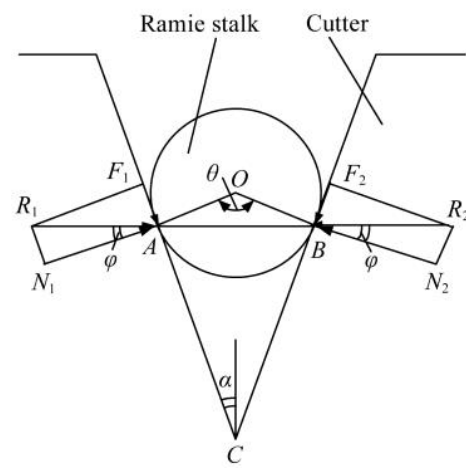

Figure 3 Force analysis of clamped ramie stalk 
There are positive pressure $N_{1}, N_{2}$ and friction force $F_{1}, F_{2}$ $\left(F_{1} \leq N_{1} \operatorname{tg} \varphi, F_{2} \leq N_{2} \operatorname{tg} \varphi\right)$ at the contact points $A$ and $B$ of the blade and ramie stalk. The cutting angle of the blade is $\alpha$. The resultant force of the positive pressure and friction force is expressed by $R_{1}$ and $R_{2}$ respectively. The condition for the blade to clamp ramie stalk is that the resultant force $R_{1}$ and $R_{2}$ acting on the two contact points are in the same straight line.

As can be seen from the triangle $O A B$ in Figure 3 ,

$$
\theta+2 \varphi=\pi
$$

where, $\varphi$ is the friction angle between the blade and the ramie stalk, $\left({ }^{\circ}\right)$.

In the quadrangle $O A C B, \angle O A C=\angle O B C=\pi / 2$, that is

$$
\theta+2 \alpha=\pi
$$

where, $\alpha$ is the cutting angle of the blade, $\left(^{\circ}\right)$.

By combining the above two equations, we can get:

$$
\alpha=\varphi
$$

To sum up, it can be concluded that the condition for the ramie stalk to be clamped are:

$$
\alpha \leq \varphi
$$

That is, the cutting angle of the blade should be less than the friction angle between the blade and the ramie stalk. The blade selected for ramie harvester is $79 \mathrm{~mm}$ in blade height, $66 \mathrm{~mm}$ in blade bottom width, $16 \mathrm{~mm}$ in front bridge width, $4 \mathrm{~mm}$ in blade thickness, $18^{\circ}$ in cutting angle $\alpha$, and $10 \mathrm{~mm}$ in bottom edge spacing between adjacent blades. The friction angle between movable blade and ramie stalk is $26^{\circ}-29^{\circ}$ measured in the test, so the selected blade meets the clamping conditions.

\subsubsection{Analysis of cutter movement}

The movement of the cutter can be simplified into a simple harmonic motion, as shown in Figure 4, which can be represented by the movement of the projection point $\mathrm{A}$ of the crank pin on the horizontal diameter.

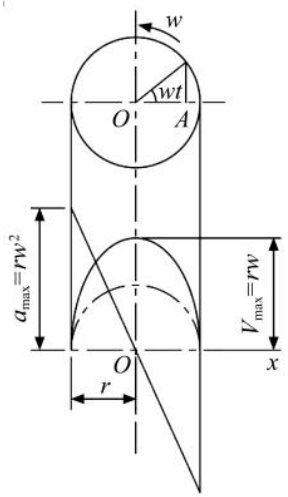

Figure 4 Schematic diagram of cutter movement

Taking the crank center $O$ as the origin and the right side of the $x$-axis as positive, the displacement, speed and acceleration of the cutter are:

$$
\left\{\begin{array}{l}
x=r \cos w t \\
v=\frac{d x}{d t}=-r w \sin w t \\
a=\frac{d^{2} x}{d t}=-r w^{2} \cos w t
\end{array}\right.
$$

where, $x$ is the displacement of cutter, $\mathrm{m} ; v$ is the speed of cutter, $\mathrm{m} / \mathrm{s} ; a$ is the acceleration of cutter, $\mathrm{m} / \mathrm{s}^{2} ; w$ is the angular speed of crank, $\mathrm{rad} / \mathrm{s} ; r$ is the radius of crank, $\mathrm{m}$.

It can be seen from Equation (5) that the displacement, speed and acceleration of the cutter are all functions of time $t$, and the change rule is the sine or cosine curve. The relation between the displacement and speed and acceleration of the cutter is as follows:

$$
\left\{\begin{array}{l}
\frac{x^{2}}{r^{2}}+\frac{v^{2}}{(r w)^{2}}=1 \\
a=-w^{2} x
\end{array}\right.
$$

From Equation (6), it can be seen that the displacement of the cutter is in an elliptical relationship with the speed, and the displacement of the cutter is in a linear relationship with the acceleration.

3.1.3 Relationship between cutting speed and forward speed

In the design of agricultural machinery, the relationship between the cutting speed and the forward speed is expressed by the advance distance. The so-called advance distance is the distance the machine advances within the time the cutter completes a stroke. The advance distance of the cutter directly affects the scanning area of the moving blade (edge) to the ground. The cutting diagram is shown in Figure 5.

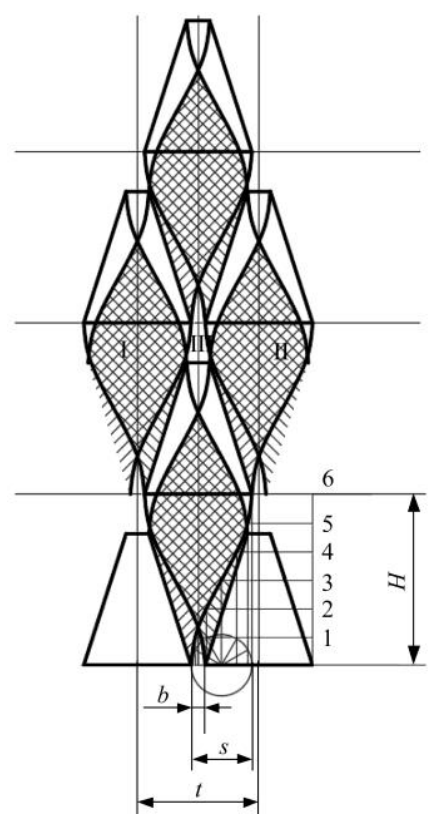

Note: $s$ is the cutter's stroke; $b$ is blade clearance; $t$ is the distance between the center lines of adjacent blades; area I and II are the areas that have been cut once; area III is the missed area.

Figure 5 Cutting diagram of double movable blades cutter

The advance distance of the cutter has a great impact on the working performance of the cutter. It not only affects the working load and cutting ability of the cutting blade, but also is an important parameter to determine the crank speed of the cutter. The calculation equation of the cutter's advance distance is:

$$
H=v_{m} \frac{\pi}{\omega}=\frac{30 v_{m}}{n}
$$

where, $H$ is the advance distance, $\mathrm{mm} ; v_{m}$ is the forward speed of the machine, $\mathrm{m} / \mathrm{s} ; w$ is the angular speed of crank, $\mathrm{rad} / \mathrm{s} ; n$ is the revolving speed of the crank, $\mathrm{r} / \mathrm{min}$.

The relation between the speed of cutter and the forward speed of machine can be expressed by cutting speed ratio $K$ :

$$
K=\frac{v_{f}}{v_{m}}=\frac{s n / 30}{H n / 30}=\frac{s}{H}
$$

where, $v_{f}$ is the average speed of the cutter, $\mathrm{m} / \mathrm{s} ; s$ is the cutting stroke of double movable blades cutter, $\mathrm{mm}$.

The cutting speed ratio has a great impact on cutting performance. If the cutting speed ratio $K$ is too small, it will lead to irregular cutting stubble, missed cutting and unstable cutting quality; if the cutting speed ratio $\mathrm{K}$ is too large, repeated cutting may occur, resulting in power waste ${ }^{[32]}$. 
According to the planting pattern and planting density of ramie and the analysis of the cutting diagram of the double movable blades cutter, the forward speed of the ramie harvester is preliminarily selected as $0.6-1.0 \mathrm{~m} / \mathrm{s}$. In order to reduce the omission cutting of the ramie stalk and waste of power consumption during the harvest, the cutting speed, cutting speed ratio $K$ and revolving speed of the crank shall be $1.0-1.4 \mathrm{~m} / \mathrm{s}$, 1.4-1.67 and 197-276 r/min, respectively.

\subsection{Design of double-layer chain conveyor}

The function of the double-layer chain conveyor is to transport the ramie stalk to the baling device stably and smoothly after being cut by the reciprocating double movable blades cutter, ensuring that no tilting, overturning, or blocking occurs during the conveyance of the stalks. It is mainly composed of conveyor frame, upper and lower conveying chains with teeth, driving sprocket, driven sprocket, etc., as shown in Figure 6.

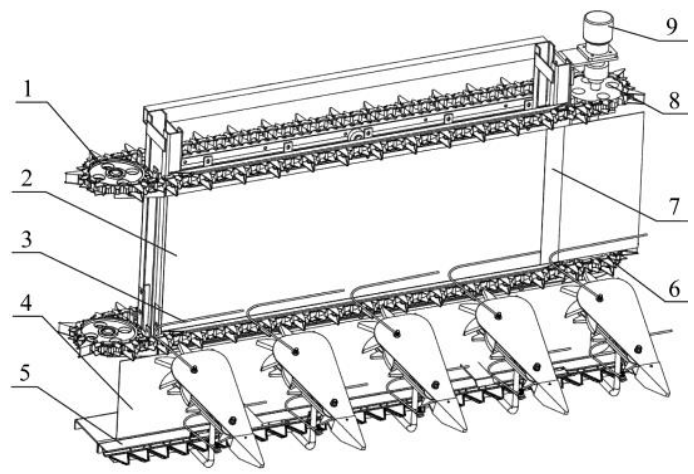

1. Driven sprocket 2. Upper baffle 3. Compression spring 4. Lower baffle 5. Baseplate 6. Conveying chain with teeth 7. Conveyor frame 8. Driving sprocket 9. Motor

Figure 6 Structure schematic of double layer chain conveyor

The upper and lower driving sprockets are connected by universal joints to realize synchronous conveyance of the upper and lower conveying chains with teeth.

3.2.1 Conditions for horizontal conveyance of ramie stalks

The ramie stalks cut off enter the horizontal conveying device under the action of the stalk-splitting and stalk-holding device, and are horizontally conveyed under the action of the conveying chain teeth. In order to ensure that the ramie stalks can be conveyed smoothly without turning over at the same time, the transport conditions of ramie stalks need to be analyzed. In the process of conveying, the forces acting on the ramie stalk are shown in Figure 7.

For the horizontal conveying of ramie stalks, the following mechanical relations shall be satisfied:

$$
F_{1}+F_{2} \geq f_{1}+f_{2}+f_{3}+f_{4}
$$

where, $F_{1}$ and $F_{2}$ are the force of the chain teeth on the ramie stalk; $f_{1}$ is the friction resistance of the base plate on the ramie stalk; $f_{2}$ is the friction resistance of the lower baffle on the ramie stalk; $f_{3}$ is the friction resistance of the upper baffle on the ramie stalk; $f_{4}$ is the traction force between the ramie stalks.

In order to prevent the ramie stalks from falling off or turning, the mechanical relationship should be satisfied: the forces in horizontal and vertical directions should be balanced respectively, and the moment at point $C M c=0$.

$$
\left\{\begin{array}{l}
\sum M_{1}=F_{1} \cdot l_{2}+F_{2} \cdot l_{4}-f_{2} \cdot l_{1}-\left(f_{3}+f_{4}\right) \cdot l_{3}=0 \\
\sum M_{2}=P_{2} l_{1}-P_{1} l_{2}+\left(P_{3}-P_{4}\right) \cdot l_{3}+P_{5} \cdot l_{5}=0
\end{array}\right.
$$

where, $P_{5}$ is the guiding force of the upper stalk-guiding device; $P_{4}$ is the supporting force of the baffle; $P_{2}$ and $P_{3}$ are the pressure of the compression spring on the ramie stalk; $P_{1}$ is the supporting force of the chain; $l_{1}, l_{2}, l_{3}, l_{4}$ and $l_{5}$ are the vertical distance from the acting points of $f_{2}, F_{1}, f_{3}, f_{4}, F_{2}$ and $P_{5}$ to the baseplate respectively.
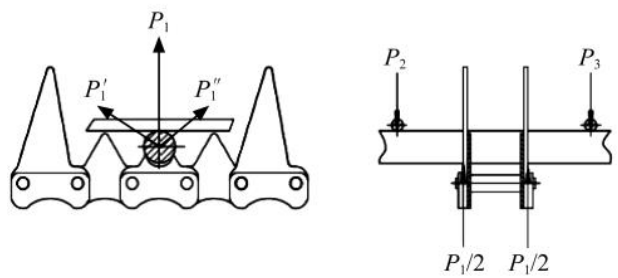

a. Force analysis of ramie stalk at holding position

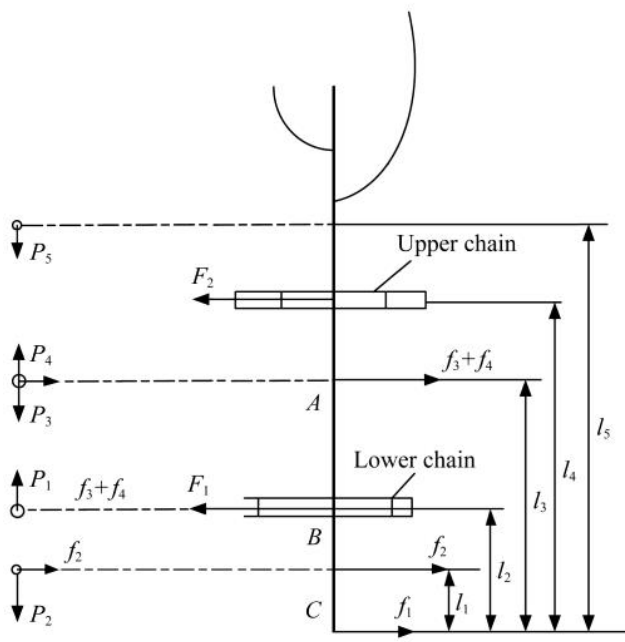

b. Force analysis of ramie stalk on the conveying chain

Figure 7 Force analysis of ramie stalk

The stalk height of ramie is measured from $1600 \mathrm{~mm}$ to $2100 \mathrm{~mm}$. According to the previous design experience and consulting the Manual of Agricultural Machinery, it is preliminarily determined that the distance between the lower conveying chain and the baseplate, the distance between the upper conveying chain and the baseplate, and the height of header shall be $380 \mathrm{~mm}, 1010 \mathrm{~mm}$ and $1240 \mathrm{~mm}$ respectively.

3.2.2 Relationship between conveying speed and forward speed

During operation, a small space is formed between the two adjacent star gear teeth, the stalk-holding device, the conveying chain teeth and the conveying chain to accommodate the ramie stalks that have been cut and convey them to the side. As shown in Figure $8, S_{0}$ is used to represent the effective capacity (area) of this small space ${ }^{[33]}$.

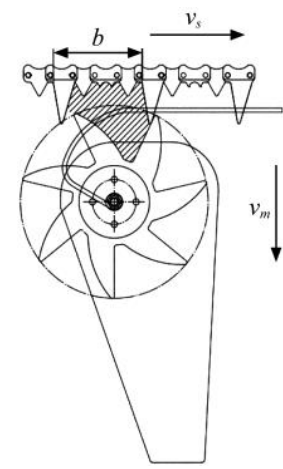

Figure 8 Schematic diagram of the convey space for ramie stalk

Within time $T$, the working area of the machine is:

$$
S=B \cdot V_{m} \cdot T
$$

where, $S$ is the working area of the machine, $\mathrm{m}^{2} ; B$ is the cutting breadth, $\mathrm{m} ; V_{m}$ is the forward speed of the machine, $\mathrm{m} / \mathrm{s}$.

The area of ramie plants accumulated in the conveying channel is 


$$
S_{1}=\frac{B \cdot V_{m} \cdot T}{q}
$$

where, $q$ represents the accumulation coefficient of ramie plants, i.e. the ratio of harvested area to accumulated area of plant, $q=s / s_{1}$.

When the conveyor chain drives the stalk-guiding star gear to rotate at a speed $V_{S}$, the total capacity $S_{2}$ covered by the stalk-guiding star gear is a multiple of the capacity $S_{0}$ between the two teeth of star gear during the same time $T$.

$$
S_{2}=S_{0} \frac{V_{s} \cdot T}{b}
$$

where, $b$ is the distance between adjacent teeth of the conveyor chain, $\mathrm{m}$.

In order to ensure the smooth conveying of ramie stalks without blocking, the total capacity $S_{2}$ covered by the stalk-guiding star gear of header shall be larger than the capacity $S_{1}$ of the accumulated ramie plants.

$$
S_{0} \frac{V_{s} \cdot T}{b} \geq \frac{B \cdot V_{m} \cdot T}{q}
$$

Then, the conveying speed and forward speed shall meet the following condition:

$$
\frac{V_{s}}{V_{m}} \geq \frac{B \cdot b}{S_{0} \cdot q}
$$

From the equation, it can be seen that the ratio of conveying speed to forward speed is related to cutting breadth $B$, teeth spacing $b$, conveying space $S_{0}$, and accumulation coefficient $q$ of ramie plants. The accumulation coefficient $q$ is related to the planting density and plant size of ramie. Based on the planting situation of ramie in the experimental base, i.e. taking the accumulation coefficient $q$ as 25 , the cutting breadth as $1800 \mathrm{~mm}$, the distance between teeth as $132 \mathrm{~mm}$, it is preliminarily determined that the speed ratio shall meet the conditions of $V_{S} / V_{m} \geq 1.5$, the forward speed shall be $0.6-1.0 \mathrm{~m} / \mathrm{s}$, and the chain conveying speed shall be $0.9-1.5 \mathrm{~m} / \mathrm{s}$.

\section{Performance testing of cutting-conveying operation}

\subsection{Test conditions and test scheme}

Due to the difference in planting patterns and varieties in different areas of ramie, it cannot be used in one machine. Ramie harvester designed in this study is suitable for ridge width more than $1 \mathrm{~m}$ and plant height of $1.5-2.5 \mathrm{~m}$. The test was carried out at the test base in Xiangyanghu Town, Xian'an District, Xianning City, Hubei Province from October 25 to 29, 2019 (as shown in Figure 9). The variety of ramie used in the test is "Huazhu No.4", with planting spacing of $2 \mathrm{~m}$, raw ramie yield of $2700 \mathrm{~kg} / \mathrm{hm}^{2}$, average plant height of $181.3 \mathrm{~cm}$, average diameter at the bottom of the ramie stalk of $11.18 \mathrm{~mm}$, and moisture content of the ramie stalk of $69.74 \%-77.31 \%$.

Based on the observation and theoretical analysis of previous single-factor experiment, the forward speed $A$, cutting speed $B$ and chain conveyor speed $C$, which have a great impact on the cutting-conveying performance, are selected as the experimental factors. Other experimental parameters include blade length of $120 \mathrm{~mm}$, horizontal distance between cutting and clamping point of $64 \mathrm{~mm}$. With cutting efficiency $Y_{1}$, failure rate $Y_{2}$ and conveying rate $Y_{3}$ as indicators of cutting-conveying operation, 17 groups of 3 -factor and 3-level orthogonal experiments were carried out ${ }^{[34,35]}$, and the center point was repeated 5 times. Experimental factors and levels are shown in Table 1.

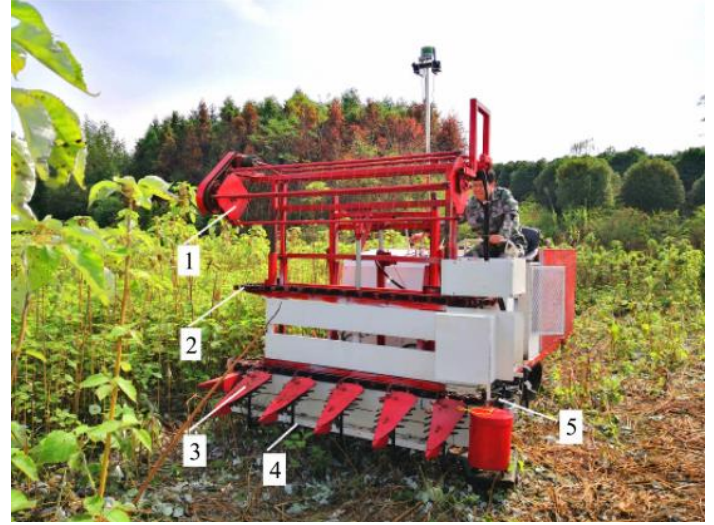

1. Upper stalk-guiding device 2. Double-layer chain conveyor 3. Lower stalk-splitting and stalk-holding device 4. Reciprocating double movable blades cutter 5. Baling device

Figure 9 Field testing of ramie harvester

Table 1 Coding table of experimental factors and levels

\begin{tabular}{lccc}
\hline \multirow{2}{*}{ factor } & \multicolumn{3}{c}{ Experimental level } \\
\cline { 2 - 4 } & -1 & 0 & 1 \\
\hline Forward speed $A / \mathrm{m} \cdot \mathrm{s}^{-1}$ & 0.6 & 0.8 & 1.0 \\
Cutting speed $\mathrm{B} / \mathrm{m} \cdot \mathrm{s}^{-1}$ & 1.0 & 1.2 & 1.4 \\
Chain conveyor speed $C / \mathrm{m} \cdot \mathrm{s}^{-1}$ & 0.9 & 1.2 & 1.5 \\
\hline
\end{tabular}

In Design-Expert.V8.0.6.1, according to the central composite design (CCD) test scheme, the test results are shown in Table 2. Through the analysis of the results in Table 2, the regression model equations of cutting efficiency $Y_{1}$, failure rate $Y_{2}$ and success rate of

\begin{tabular}{|c|c|c|c|c|c|c|}
\hline \multirow[b]{2}{*}{ No. } & \multicolumn{3}{|c|}{ Factor level } & \multicolumn{3}{|c|}{ Response value } \\
\hline & $\begin{array}{c}\text { Forward } \\
\text { Speed } \\
/ \mathrm{m} \cdot \mathrm{s}^{-1}\end{array}$ & $\begin{array}{c}\text { Cutting } \\
\text { speed } \\
\mathrm{lm} \cdot \mathrm{s}^{-1}\end{array}$ & $\begin{array}{c}\text { Chain } \\
\text { conveying } \\
\mathrm{speed} / \mathrm{m} \cdot \mathrm{s}^{-1}\end{array}$ & $\begin{array}{l}\text { Cutting } \\
\text { efficiency } \\
\text { /plants } \cdot \mathrm{s}^{-1}\end{array}$ & $\begin{array}{l}\text { Failure } \\
\text { rate/\% }\end{array}$ & $\begin{array}{c}\text { Conveying } \\
\text { rate } / \%\end{array}$ \\
\hline 1 & -1 & 0 & -1 & 32 & 28.68 & 80.55 \\
\hline 2 & 1 & 1 & 0 & 44 & 5.17 & 86.20 \\
\hline 3 & 0 & -1 & -1 & 41 & 10.65 & 83.28 \\
\hline 4 & 0 & -1 & 1 & 39 & 12.35 & 92.36 \\
\hline 5 & 0 & 1 & 1 & 44 & 4.83 & 91.27 \\
\hline 6 & 0 & 0 & 0 & 40 & 11.54 & 93.90 \\
\hline 7 & 1 & 0 & -1 & 42 & 8.76 & 75.64 \\
\hline 8 & -1 & -1 & 0 & 32 & 29.63 & 91.59 \\
\hline 9 & 1 & -1 & 0 & 38 & 13.65 & 88.84 \\
\hline 10 & 0 & 0 & 0 & 42 & 7.98 & 94.55 \\
\hline 11 & 0 & 0 & 0 & 40 & 11.39 & 93.37 \\
\hline 12 & 0 & 0 & 0 & 43 & 7.97 & 93.22 \\
\hline 13 & 1 & 0 & 1 & 46 & 4.16 & 86.56 \\
\hline 14 & -1 & 1 & 0 & 30 & 31.57 & 91.33 \\
\hline 15 & -1 & 0 & 1 & 31 & 30.87 & 84.65 \\
\hline 16 & 0 & 1 & -1 & 42 & 8.93 & 81.26 \\
\hline 17 & 0 & 0 & 0 & 42 & 8.10 & 95.51 \\
\hline
\end{tabular}
conveyance $Y_{3}$ are fitted out respectively to explore the impact of various factors on the evaluation indicators and the interaction law.

Table 2 Results and design of tests

\subsection{Test methods for test indicators}

The main evaluation indicators of cutting device are cutting efficiency and cutting quality. The cutting efficiency is analyzed and evaluated by the number of stalks cut per unit time, and the cutting quality is analyzed and evaluated by the failure rate of stalk cutting. The failure rate $Y_{2}$ is calculated by the ratio of the number of uncut stalks to the total number of stalks in the test, with 
calculation equation as follows:

$$
Y_{2}=\frac{N_{1}}{N} \times 100 \%
$$

where, $Y_{2}$ is the failure rate; $N_{1}$ is the number of uncut stalks; $N$ is the total number of stalks.

Since there is no technical standard for ramie harvesting equipment at present, the conveying rate of the conveying device is calculated by referring to the relevant standards of other crop harvesters $^{[36]}$. Conveying rate $Y_{3}$ refers to the ratio of successful conveyance of ramie stalks.

Cutting efficiency, failure rate and conveying rate are selected as three evaluation indicators. Based on the comprehensive analysis of the test results, the optimal parameter combination of cutting-conveying performance is obtained in this test.

\subsection{Results and analysis}

The test scheme and results are shown in Table 2. According to the test results, the response parameters are analyzed and a mathematical model is established.

4.3.1 Establishment of regression model and significance test

Based on the data obtained in the experiment and multiple regression fitting analysis by Design-Expert software, mathematical regression models of the three independent variables of the cutting efficiency $Y_{1}$, failure rate $Y_{2}$ and conveying rate $Y_{3}$ of the ramie harvester to the forward speed $A$, cutting speed $B$ and chain conveying speed $C$ is established as follows:

$$
\begin{aligned}
Y_{1}= & 41.40+5.63 A+1.25 B+0.38 C+2.00 A B+1.25 A C+ \\
& 1.00 B C-4.58 A^{2}-0.83 B^{2}+0.93 C^{2} \\
Y_{2}= & 9.40-11.13 A-1.97 B-0.60 C-2.60 A B-1.70 A C- \\
& 1.45 B C+9.77 A^{2}+0.84 B^{2}-1.05 C^{2} \\
Y_{3}= & 94.11-1.36 A-0.75 B+4.26 C-0.60 A B+1.70 A C+ \\
& 0.23 B C-4.91 A^{2}+0.29 B^{2}-7.35 C^{2}
\end{aligned}
$$

\begin{tabular}{|c|c|c|c|c|c|c|c|c|c|c|c|c|}
\hline \multirow{2}{*}{$\begin{array}{l}\text { Source of } \\
\text { variation }\end{array}$} & \multicolumn{4}{|c|}{ Cutting efficiency $Y_{1}$} & \multicolumn{4}{|c|}{ Failure rate $Y_{2}$} & \multicolumn{4}{|c|}{ Conveyor rate $Y_{3}$} \\
\hline & $\begin{array}{l}\text { Sum of } \\
\text { squares }\end{array}$ & $D O F$ & F-value & $\begin{array}{c}\mathrm{P} \\
\text { Significance level }\end{array}$ & $\begin{array}{l}\text { Sum of } \\
\text { squares }\end{array}$ & $D O F$ & F-value & $\begin{array}{c}\mathrm{P} \\
\text { Significance level }\end{array}$ & $\begin{array}{l}\text { Sum of } \\
\text { squares }\end{array}$ & $D O F$ & F-value & $\begin{array}{c}\mathrm{P} \\
\text { Significance level }\end{array}$ \\
\hline Model & 387.58 & 9 & 25.23 & $0.0002 * *$ & 1481.85 & 9 & 66.01 & $<0.0001 * *$ & 524.67 & 9 & 47.50 & $<0.0001 * *$ \\
\hline$A$ & 253.13 & 1 & 148.27 & $<0.0001 * *$ & 990.35 & 1 & 397.05 & $<0.0001 * *$ & 14.80 & 1 & 12.06 & $0.0104^{*}$ \\
\hline$B$ & 12.50 & 1 & 7.32 & $0.0304 *$ & 31.13 & 1 & 12.48 & $0.0096 * *$ & 4.52 & 1 & 3.68 & 0.0966 \\
\hline$C$ & 1.13 & 1 & 0.66 & 0.4436 & 2.89 & 1 & 1.16 & 0.3173 & 145.44 & 1 & 118.51 & $<0.0001 * *$ \\
\hline$A B$ & 16.00 & 1 & 9.37 & $0.0183^{*}$ & 27.14 & 1 & 10.88 & $0.0131 *$ & 1.42 & 1 & 1.15 & 0.3184 \\
\hline$A C$ & 6.25 & 1 & 3.66 & 0.0973 & 11.53 & 1 & 4.62 & 0.0686 & 11.63 & 1 & 9.48 & $0.0179^{*}$ \\
\hline$B C$ & 4.00 & 1 & 2.34 & 0.1697 & 8.41 & 1 & 3.37 & 0.1089 & 0.22 & 1 & 0.18 & 0.6872 \\
\hline$A^{2}$ & 88.13 & 1 & 51.62 & $0.0002 * *$ & 401.76 & 1 & 161.07 & $<0.0001 * *$ & 101.35 & 1 & 82.59 & $<0.0001 * *$ \\
\hline$B^{2}$ & 2.87 & 1 & 1.68 & 0.2362 & 2.98 & 1 & 1.19 & 0.3108 & 0.35 & 1 & 0.28 & 0.6124 \\
\hline$C^{2}$ & 3.60 & 1 & 2.11 & 0.1896 & 4.61 & 1 & 1.85 & 0.2160 & 227.70 & 1 & 185.54 & $<0.0001^{* *}$ \\
\hline Residual & 11.95 & 7 & & & 17.46 & 7 & & & 8.59 & 7 & & \\
\hline Lack of fit & 4.75 & 3 & 0.88 & 0.5229 & 3.17 & 3 & 0.30 & 0.8277 & 5.05 & 3 & 1.90 & 0.2702 \\
\hline Error & 7.20 & 4 & & & 14.29 & 4 & & & 3.54 & 4 & & \\
\hline Total & 399.53 & 16 & & & 1499.31 & 16 & & & 533.26 & 16 & & \\
\hline
\end{tabular}

The above equations are further analyzed, and the significance test of regression coefficients is carried out at the same time. The analysis results are shown in Table 3.

\section{Table 3 Regression equation analysis of variance results}

Note: $p<0.01$ (Extremely significant, $\left.{ }^{* *}\right) ; p<0.05$ (Significant, *).

It can be known from the analysis results of Table 3 that the $p$-values of response surface models for cutting efficiency $Y_{1}$, failure rate $Y_{2}$ and conveyor rate $Y_{3}$ are $0.0002,<0.0001$ and $<0.0001$. All are less than 0.01 , indicating that the finally obtained significance of the three models meets the requirements; the values of mismatched items in the three indexes are 0.5229 , 0.8277 and 0.2702 , which are more than 0.005 , indicating that the fitness of the three models is relatively high and meets the requirements; the determination factors, $R$, of the three models are $0.9701,0.9884$ and 0.9839 . The data shows that the fitness of the three models is relatively high and the reliability of response surface analysis results is relatively high. Hence, the model can predict and analyze the changes in the operational performance of ramie harvester.

It can be known from the aforesaid significance analysis that the influence of $A$ and $A^{2}$ in the response surface model of cutting efficiency $Y_{1}$ on the model is significant. The influence of $A, B$ and $A^{2}$ in the response surface model of failure rate $Y_{2}$ on the model is extremely significant and the influence of $A B$ on the model is significant. The influence of $C, A^{2}, C^{2}$ in the response model of conveyor rate $Y_{3}$ on the model is extremely significant and the influence of $A$ and $A C$ on the model is significant. The items that exert no significant influence on the regression model in the aforesaid model are removed. Meanwhile, on the basis of ensuring that the model $p<0.01$ and the mismatched item $p>0.05$, the simplified regression model is obtained as below:

$$
\begin{gathered}
Y_{1}=41.40+5.63 A+1.25 B+2.00 A B-4.58 A^{2} \\
Y_{2}=9.40-11.13 A-1.97 B-2.60 A B+9.77 A^{2} \\
Y_{3}=94.11-1.36 A+4.26 C+1.70 A C-4.91 A^{2}-7.35 C^{2}
\end{gathered}
$$

It can be known from the analysis that the influencing effects of the three factors on cutting efficiency rank as $A>B>C$. The influencing effects of the three factors on failure rate rank as $A>B>C$. The influencing effects of the three factors on conveyor rate rank as $C>A>B$.

4.3.2 Influence of interactive factors on evaluation indexes

A certain factor is fixed at the intermediate level to analyze the interactive effects of the other two factors on evaluation indexes. Through plotting the response surface and contour plots, the influence of advancing speed, cutting speed and chain conveying speed of the three influencing factors on evaluation indexes is analyzed.

(1) Analysis of influence law of interactive factors on cutting efficiency

The response surface curves of the influence of the interactive 
factors, namely advancing speed, cutting speed and chain conveying speed, on cutting efficiency are shown in Figure 10. Figure 10a shows that the chain conveying speed remains at the intermediary level, that is, $C=1.2 \mathrm{~m} / \mathrm{s}$ and the response surface plot of interactive effects of advancing speed and cutting speed on cutting efficiency. It can be seen from Figure 10a that the interactive effects between the two factors are significant. When the cutting speed remains at a lower level, the cutting efficiency increases first and decreases afterward as the advancing speed increases. When the cutting speed remains at a higher level, the cutting efficiency rapidly increases as the advancing speed increases. The influence of cutting speed on cutting efficiency is not so significant as that of advancing speed because the increase of advancing speed can lead to irregular stubble cutting, missed cutting, lower cutting efficiency at a lower cutting speed and the increase of feeding quantity of stalks can improve the cutting efficiency at a higher cutting speed.

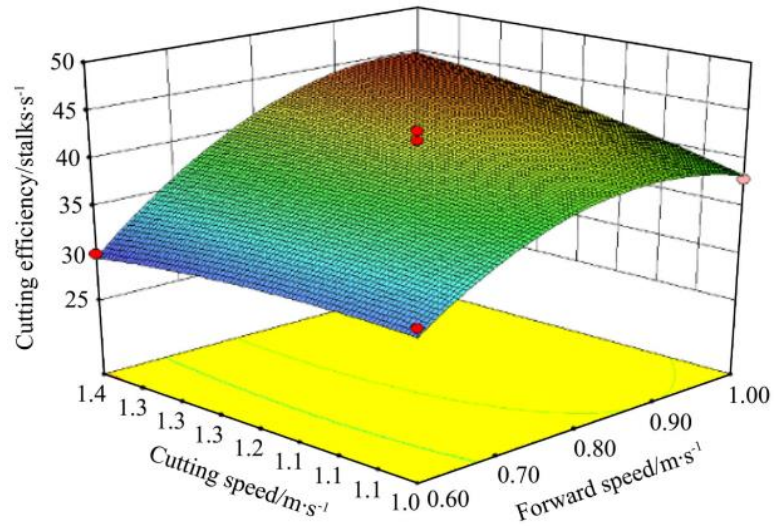

a. $Y_{1}=f(A, B, 0)$

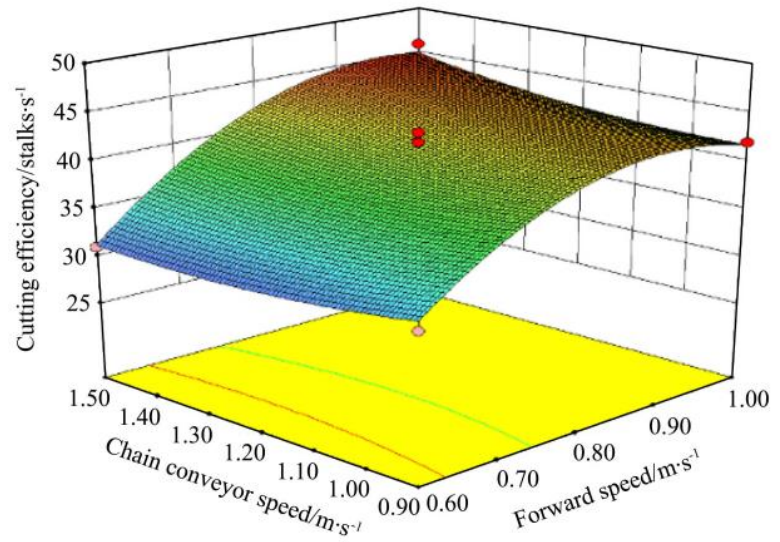

b. $Y_{1}=f(A, 0, C)$

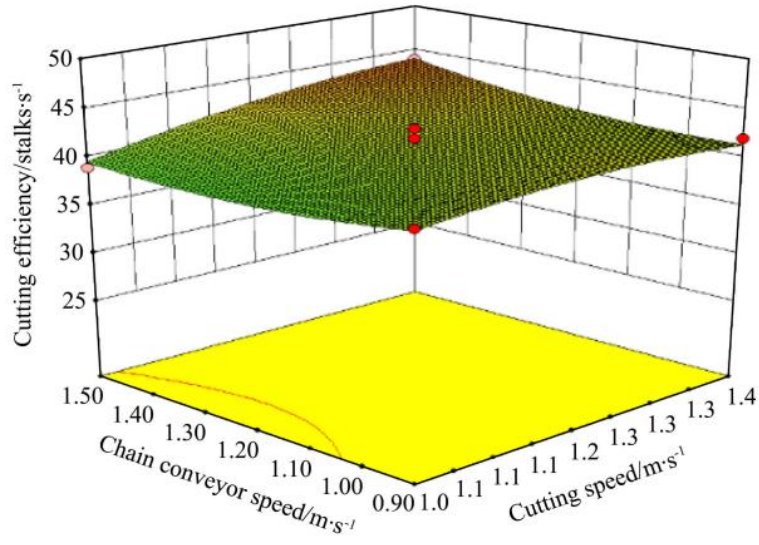

c. $Y_{1}=f(0, B, C)$

Figure 10 Influence of interactive factors on the cutting efficiency
As shown in Figure $10 \mathrm{~b}$, the cutting speed remains at the intermediary level, that is, $B=1.2 \mathrm{~m} / \mathrm{s}$ and the response surface plot of interactive effects of advancing speed and chain conveying speed on cutting efficiency. It can be seen from Figure 10b that the interactive effects between the two factors are not significant. Under the same chain conveying speed, the cutting efficiency improves as the advancing speed increases because the increase of advancing speed improves the stalk feeding quantity. Under the same advancing speed, the influence of chain conveying speed on cutting efficiency is relatively small.

As shown in Figure 10c, the advancing speed remains at the intermediary level, that is, $A=0.8 \mathrm{~m} / \mathrm{s}$ and the response surface plot of interactive effects of cutting speed and chain conveying speed on cutting efficiency. It can be seen from Figure $10 \mathrm{c}$ that the interactive effects between the two factors are not significant. Under the same chain conveying speed, the cutting efficiency slowly improves as the chain conveying speed increases because improving chain conveying speed can facilitate conveying the cut stalks and reducing stalk obstruction of cutting channels. Under the same chain conveying speed, the cutting efficiency increases as the cutting speed increases because the increase of cutting speed can reduce the missed cutting of stalks.

(2) Analysis on influence of interactive factors on failure rate

The response surface curve of influence of interactive factors, including advancing speed, cutting speed and chain conveying speed, on failure rate is shown in Figure 11.

In Figure 11a, the chain conveying speed remains at the intermediary level, that is, $C=1.2 \mathrm{~m} / \mathrm{s}$ and the response surface plot of interactive effects of advancing speed and cutting speed on failure rate. It can be seen from Figure 11a that the interactive effects between the two factors are significant. The influence of cutting speed on failure rate is not so significant as that of advancing speed. Under the same cutting speed, the failure rate rapidly decreases first and slowly increases then with the increase of advancing speed because the increase of advancing speed at the very beginning lowers the re-cutting rate of stalks and vibration caused by power waste, and facilitates the cutting of cutter to lower the failure rate of cutting. When the advancing speed exceeds the cutter cutting ability, there will be irregular stubble cutting and missed cutting, which increases the failure rate.

In Figure $11 \mathrm{~b}$, the cutting speed remains at the intermediary level, that is, $B=1.2 \mathrm{~m} / \mathrm{s}$ and the response surface plot of interactive effects of advancing speed and chain conveying speed on failure rate. It can be seen from Figure $11 \mathrm{~b}$ that the interactive effects between the two factors are not significant. Under the same chain conveying speed, the failure rate rapidly decreases with the increase of advancing speed. Under the same advancing speed, the influence of chain conveying speed on failure rate is relatively small.

In Figure $11 \mathrm{c}$, the advancing speed remains at the intermediary level, that is, $A=0.8 \mathrm{~m} / \mathrm{s}$ and the response surface plot of interactive effects of cutting speed and chain conveying speed on failure rate. It can be seen from Figure 11c that the interactive effects between the two factors are not significant. Under the same chain conveying speed, the failure rate slowly decreases with the increase of cutting speed. Under the same cutting speed, the failure rate basically remains unchanged with the increase of chain conveying speed and the influence of chain conveying speed on failure rate is not so significant as that of cutting speed. 


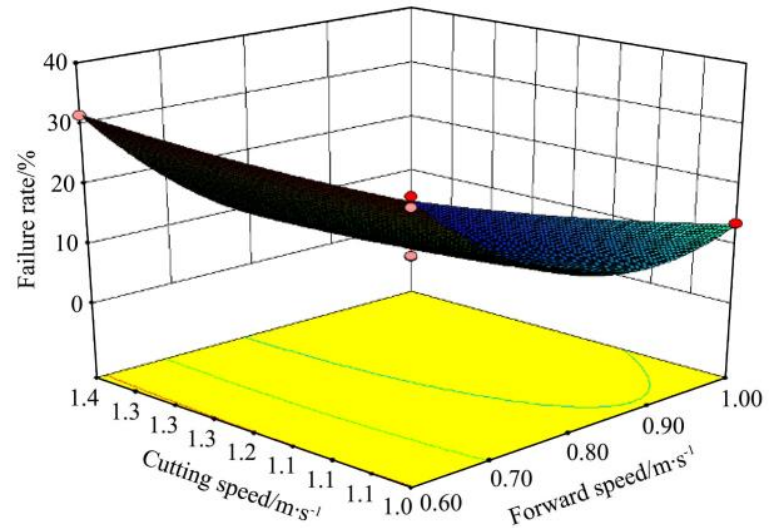

a. $Y_{2}=f(A, B, 0)$

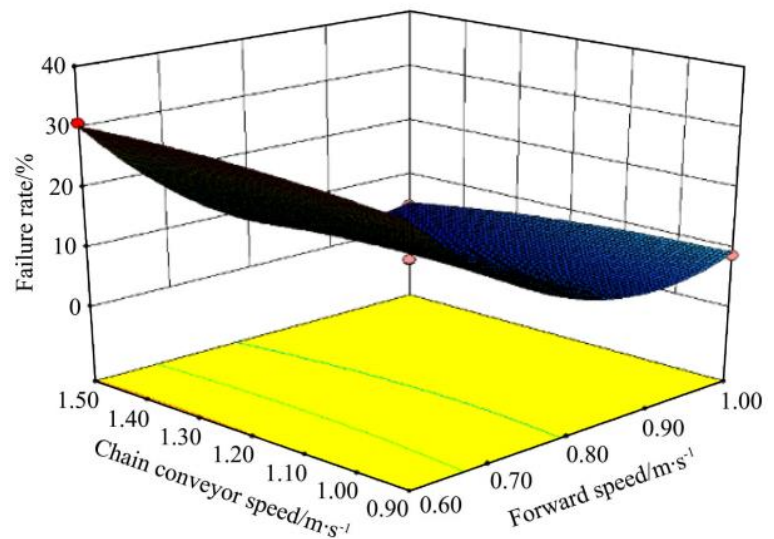

b. $Y_{2}=f(A, O, C)$

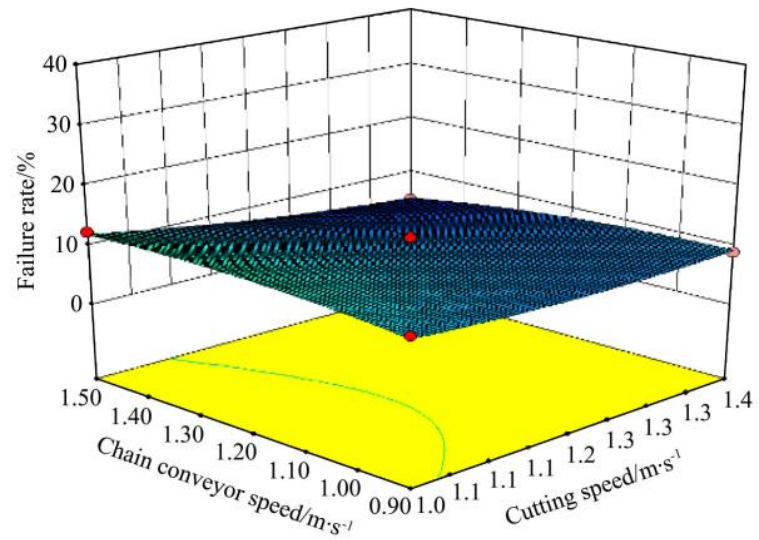

c. $Y_{2}=f(0, B, C)$

Figure 11 Influence of interactive factors on the failure rate

(3) Analysis on influence of interactive factors on conveyor rate

The response surface curve plot of influence of interactive factors, including advancing speed, cutting speed and chain conveying speed, on conveyor rate is shown in Figure 12.

In Figure 12a, the chain conveying speed remains at the intermediary level, that is, $C=1.2 \mathrm{~m} / \mathrm{s}$ and the response surface plot of interactive effects of advancing speed and cutting speed on conveyor rate. It can be seen from Figure 12a that the interactive effects between the two factors are not significant. Under the same cutting speed, the conveyor rate rapidly increases first and decreases then with the increase of advancing speed because the increase of advancing speed at the beginning lowers the falling of cut stalks, facilitates the chain conveying and rapidly accelerates the conveyor rate. When the advancing speed is too high, there will be not enough time to harvest the stalks and the stalks will be pushed down heading forward. There will be irregular stubble cutting and missed cutting, not facilitating the chain conveying and further lowering the conveyor rate.

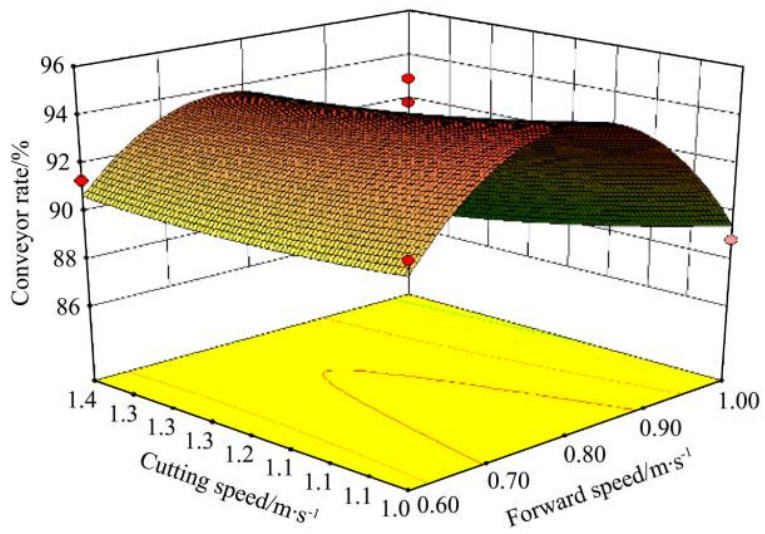

a. $Y_{3}=f(A, B, 0)$

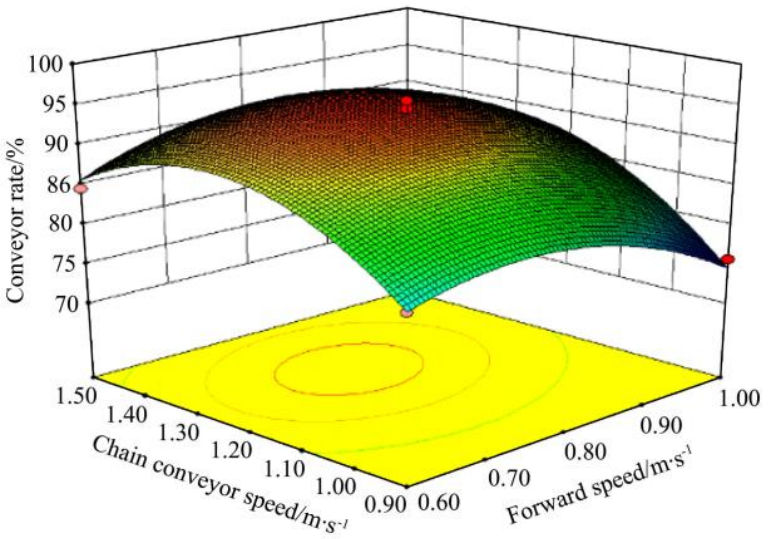

b. $Y_{3}=f(A, 0, C)$

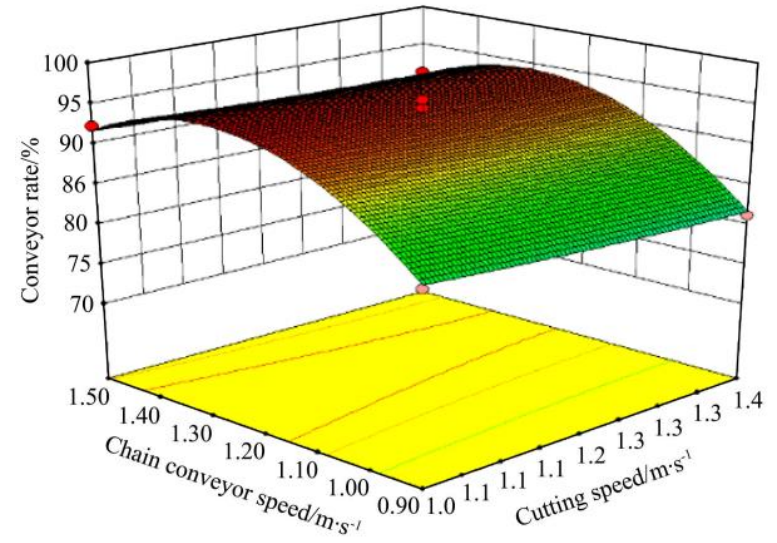

c. $Y_{3}=f(0, B, C)$

Figure 12 Influence of interactive factors on the conveyor rate

In Figure 12b, the cutting speed remains at the intermediary level, that is, $B=1.2 \mathrm{~m} / \mathrm{s}$ and the response surface plot of interactive effects of advancing speed and chain conveying speed on conveyor rate. It can be seen from Figure $11 \mathrm{~b}$ that the interactive effects between the two factors are significant. Under the same chain conveying speed, the conveyor rate increases first and decreases then with the increase of advancing speed. Under the same advancing speed, the conveyor rate increases first and decreases then with the increase of chain conveying speed. The increase of chain conveying speed at the beginning lowers the falling of stalks and facilitates the conveying. When the chain conveying speed is too high, the chain gears form a closed surface, not facilitating the entry of stalks into chains for conveying and lowering the conveyor rate.

In Figure 12c, the advancing speed remains in the intermediary 
level, that is, $A=0.8 \mathrm{~m} / \mathrm{s}$ and the response surface plot of interactive effects of cutting speed and chain conveying speed on conveyor rate. It can be seen from Figure $11 \mathrm{c}$ that the interactive effects between the two factors are not significant. Under the same cutting speed, the conveyor rate increases first and decreases then with the increase of chain conveying speed. Under the same chain conveying speed, the influence of cutting speed on conveyor rate is relatively small.

\subsection{Parameter optimization and experiment verification}

\subsubsection{Parameter optimization}

Combined with the analysis above, in order to optimize the performance of ramie harvester, it is required to maximize the cutting efficiency and conveyor rate and minimize the failure rate. In order to seek the optimal parameter combination, it is required to conduct the parameter optimization on multiple targets. According to the actual production and design requirements and referring to other relevant standards, the cutting efficiency is required to be more than $35 \mathrm{stalks} / \mathrm{s}$. The failure rate is required to be less than $10 \%$ and the conveyor rate is required to be more than 90\%. Hence, the constraint conditions are listed below:

$$
\left\{\begin{array}{l}
Y_{1} \geq 35 \\
Y_{2} \leq 10 \% \\
Y_{3} \geq 90 \% \\
0.6 \leq A \leq 1.0 \\
1.0 \leq B \leq 1.4 \\
0.9 \leq C \leq 1.5
\end{array}\right.
$$

Design-Expert was used to optimize and solve each parameter. The optimal solutions are: advancing speed $0.85 \mathrm{~m} / \mathrm{s}$, cutting speed $1.40 \mathrm{~m} / \mathrm{s}$, chain conveying speed $1.33 \mathrm{~m} / \mathrm{s}$, cutting efficiency $44.36 \mathrm{stalks} / \mathrm{s}$, failure rate $4.16 \%$, conveyor rate $93.60 \%$.

4.4.2 Experiment verification

In order to verify the accuracy of models above, on October 29, 2019, the verification experiment was conducted in Experiment Base in Xiangyanghu Town, Xian'an District, Xianning City, Hubei Province with the same ramie growth and experiment method as previously. Before the experiment, the moisture content of ramie stalk was $70.21 \%$ and the stalk height was $179.45 \mathrm{~cm}$ on average and the average diameter of stalk bottom was $11.03 \mathrm{~mm}$. Given the feasibility of experiment parameter setting, the optimized parameters were set as advancing speed $0.85 \mathrm{~m} / \mathrm{s}$, cutting speed $1.40 \mathrm{~m} / \mathrm{s}$, and chain conveying speed $1.30 \mathrm{~m} / \mathrm{s}$. In terms of experiment results, the cutting efficiency was measured as 43.80 stalks/s; the failure rate was measured as $4.52 \%$; the conveyor rate was measured as $92.45 \%$. The relative errors between the experiment values and optimized values are $1.3 \%, 8.7 \%$ and $1.2 \%$, indicating that the results are relatively consistent. The research results can provide reference for mechanism improvement of ramie combine harvester and operational parameter control.

\section{Conclusions}

(1) A cutting-conveying mechanism suitable for ramie combine harvesting operation is researched and produced in this paper. It mainly consists of compound double-moving-cutter cutter and double-layer chain conveyor, which effectively solves the difficulties, such as irregular stubble cutting, low cutting efficiency and conveying breaking and obstructing, in the cutting-conveying links of ramie combine harvester.

(2) The parameter optimization model of ramie mechanical harvesting is established to obtain the optimal parameter combination where the cutting efficiency and conveyor rate reach the maximum while the failure rate reaches the minimum: advancing speed $0.85 \mathrm{~m} / \mathrm{s}$, cutting speed $1.4 \mathrm{~m} / \mathrm{s}$, chain conveying speed $1.3 \mathrm{~m} / \mathrm{s}$. Under the parameter condition, the field experiment detection is conducted where the cutting efficiency is $43.80 \mathrm{stalks} / \mathrm{s}$, the failure rate is $4.52 \%$ and the conveyor rate is $92.45 \%$, which can provide a reference for mechanism improvement of ramie combine harvester and operational parameter control.

\section{Acknowledgements}

The authors greatly appreciate the careful and precise reviews by the anonymous reviewers and editors. This research was financially supported by the Fundamental Research Funds for Central Non-profit Scientific Institution (S201932), National Key R\&D Program of China (2016YFD0701404), earmarked fund for China Agriculture Research System (CARS-16-E20), the Agricultural Science and Technology Innovation Program of the Chinese Academy of Agricultural Sciences (ASTIP, CAAS).

\section{[References]}

[1] Zhu R, Yang F, Zhou B, Li Y, Lin N, Yang Y, et al. Origin, distribution of boehmeria nivea and its history of cultivation and utilization in China. Chinese Agricultural Science Bulletin, 2014; 30(12): 258-266. (in Chinese)

[2] Shen C, Li X W, Zhang B, Tian K P, Huang J C, Chen Q M. Bench experiment and analysis on ramie stalk cutting. Transactions of the CSAE 2016; 32(1): 68-76. (in Chinese)

[3] Shen C, Li X W, Tian K P, Zhang B, Huang J C, Chen Q M. Experimental analysis on mechanical model of ramie stalk. Transactions of the CSAE, 2015; 31(20): 26-33. (in Chinese)

[4] Xiong H P. Research on sustainable development strategy of modern agricultural industry in China. Beijing: China Agriculture Press, 2017. (in Chinese)

[5] Wang H W, Dai Q Z, Hou Z P, Wang Y Z, Wu D Q. Feed ramie: silage characteristics and comparison of nutrient composition and feeding value before and after silage. Chinese Journal of Animal Nutrition, 2018; 30(1): 293-298. (in Chinese)

[6] He Y, Cui H H, Tian W, Chen L M, Wang H R. The potential of ramie as forage resources for herbivorous animal and its advance in feeding value. Feed Industry magazine, 2016; 37(21): 26-30. (in Chinese)

[7] Wu D Q, Wei Z S, Gao S, Li Z C, Zeng G Z, Hou Z P, et al. Effects of replacing different partial alfalfa hay with ramie silage on performance, milk composition and serum parameters of dairy cows. Chinese Journal of Animal Nutrition, 2017; 29(5): 1645-1651. (in Chinese)

[8] Tian J. Pharmacognostic identification of boehmeriae radix. Asia-Pacific Traditional Medicine, 2019; 15(8): 74-76. (in Chinese)

[9] Chen B F, Chen J H, Mu B, Zeng M, Zhang H, Yu J, et al. Advances in medicinal health protection studies of boehmeria jacq.spp. Plant Fiber Sciences in China, 2016; 38(5): 237-241. (in Chinese)

[10] Liu X, Cheng L. Influence of surface treatment on property of ramie fiber reinforced composite. New Chemical Materials, 2018; 46(1): 140-143, 149. (in Chinese)

[11] Yu M M, Zhang H H, Liu Z M, Ge Z, Kong F G, Shao H L, et al. Effects of fiber dimension and its distribution on the properties of lyocell and ramie fibers reinforced polylactide composites. Fibers and Polymers, 2019; 20(8): 1726-1732.

[12] Anna Dilfi K F, Che Z J, Xian G J. Grafting of nano-silica onto ramie fiber for enhanced mechanical and interfacial properties of ramie/epoxy composite. Journal of Zhejiang University Science A (Applied Physics \& Engineering), 2019; 20(9): 660-674

[13] Li X L, She W, Bai Y C, Liu N N, Huang M S, Yang R F, et al. Ramie by-products utilization and intercropping patterns for mature-ramie field. Chinese Agricultural Science Bulletin, 2016; 32(33): 109-113. (in Chinese)

[14] Zhang X, Xiong C L, Jie Y C. Study on oyster mushroom cultivation with by-product of mechanical processing of ramie. Crop Research, 2013; 27(5): 457-460. (in Chinese)

[15] Lv J N, Long C H, Zhao J, Ma L, Lv H B, Liu J J, et al. Design and 
experiment of transverse-feeding ramie decorticator. Transactions of the Chinese Society of Agricultural Engineering, 2013, 29(16): 16-21. (in Chinese)

[16] Tian X J, Guo K J, Zhang D S, Su N, Man D W, Yuan X J. Design of the lifting ramie decorticator. Journal of Forestry Engineering, 2019; 4(3): 106-111. (in Chinese)

[17] Xiang W, Ma L, Liu J J, Xiao L, Long C H, Wen Q H, et al. Research progress on technology and equipment of ramie fibre stripping and processing in China. Journal of Agricultural Science and Technology, 2019; 21(11): 59-69. (in Chinese)

[18] Tang S W, Liu K, Dai Q Z, Wei Z S, Liu T M, Wang Y Z, et al. Research on mechanized harvesting and technology with agronomic intergration for forage ramie. Plant Fiber Sciences in China, 2018; 40(5): 226-233. (in Chinese)

[19] Liu J J, Long C H, Ma L, He H B, Lv J N. Feeding-ramie silage processing technology and the current situation and development trend of processing machine in China. Siliao Gongye, 2016; 37(21): 18-21. (in Chinese)

[20] Wang S, Zhang B, Li X W, Shen C, Tian K P, Huang J C. Research status on thick stalk crop cutting device and its problems and development proposals. Journal of Agricultural Mechanization Research, 2017; 39(8): 263-268. (in Chinese)

[21] Huang J C, Shen C, Ji A M, Tian K P, Zhang B, Li X W, et al. Design and test of two-wheeled walking hemp harvester. Int J Agric \& Biol Eng, 2020; 13(1): 127-137.

[22] Huang J C, Shen C, Li X W, Tian K P, Chen Q M, Zhang B. Design and tests of hemp harvester. International Agricultural Engineering Journal, 2017; 26(2): 117-127

[23] He H P, Shen C, Li X W, Zhang B, Chen Q M, Huang J C, et al. Status and prospect of reed harvesting equipment in China. International Agricultural Engineering Journal, 2019; 28(3): 128-136.

[24] Zhu H, Zhang Z G, Yu G. Development and test of hemp swather. Agricultural Engineering, 2018; 8(2): 95-98. (in Chinese)

[25] Huang J C, Li X W, Zhang B, Tian K P, Shen C, Wang J G. Research on the 4LMZ160 crawler ramie combine harvester. Journal of Agricultural Mechanization Research, 2015; 9: 155-158, 163. (in Chinese)

[26] Long $\mathrm{C} \mathrm{H}$. The existing problem and countermeasure of bast fibe harvester at home and abroad. Plant Fiber Sciences in China, 2007; 29(S2): 420-424. (in Chinese)

[27] Pari L, Baraniecki P, Kaniewski R, Scarfone A. Harvesting strategies of bast fiber crops in Europe and in China. Industrial Crops and Products, 2015; 68: 90-96.

[28] Geng R Y, Zhang D L. New Agricultural Mechanics. Beijing: Nationa Defense Industry Press, 2011. (in Chinese)

[29] Liu Z G, Wang D C, Zhai G X, Liu G L, Zhang N, Hao X Y. Design and experiment on reciprocating double knife shrub harvester. Transactions of the CSAM, 2013; 44(Supp. 2):102-106. (in Chinese)

[30] Xu X Y, Zhang W Q, Yang H M, Qi X D. Design and kinematic analysis of double-acting cutting device of walk-type pasture reaper. Transactions of the CSAE, 2011; 27(7): 156-161. (in Chinese)

[31] Ran J H, Mu S L, Li H T, Guan Z H, Tang Q, Wu C Y. Design and test of planet gear driver of reciprocating double-acting cutter for rapeseed combine harvester. Transactions of the CSAE, 2020; 36(9):17-25. (in Chinese)

[32] Song Z H, Song H L, Geng A J, Li Y D, Yan Y F, Li F D. Experiment on cutting characteristics of cotton stalk with double supports. Transactions of the CSAE, 2015; 31(16): 37-45. (in Chinese)

[33] Wang X S, Liu D W, Li X, Xie F P, Wu M L, Luo H F. Design and experiment of 4SY-2.0 self-propelled rape windrower. Journal of Hunan Agricultural University (Natural Sciences), 2016; 42(4): 445-453.

[34] Xu X H, He M Z. Experimental design and application of Design-Expert SPSS. Beijing: Science Press Co., Ltd, 2006; 205p. (in Chinese)

[35] Pan L J, Chen J Q. Experimental design and data processing. Nanjing. Southeast University Press, 2008; 257p. (in Chinese)

[36] Wang F C, Zhou X J, Shi Q X, Liu S D, Ni C A, Yao L L. Parameters study on transverse transport of new corn combine. Journal of Agricultural Mechanization Research, 2010; 36(5): 152-155. (in Chinese) 